\title{
Importance of an Efficient Warehouse Management System
}

\section{Shashidharan ${ }^{a}$, Dr. Shameem Anwar ${ }^{b}$}

aResearch Scholar, AMET Business School, Academy of Maritime Education and Training (AMET), India.

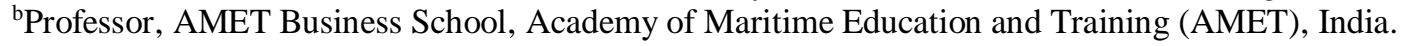

Article History: Received: 11 January 2021; Accepted: 27 February 2021; Published online: 5 April 2021

\begin{abstract}
In the preview of efficient supply chain management, the warehouse operations play a vital role. The warehouse operation is crucial since it act as the hub were the nodes are connected to the respective spokes. In the current environment it is very much essential to become competitive in a sustainable way. The warehousing operation is the key in order to meet the customers demand and hence it has to be continuously improved. The continuous improvement can be in a way obtained by being flexible in meeting the customers demand based upon their unique requirements. In this article the efficiency of the overall performance of warehouse operation is studied using questionnaire as the tool.
\end{abstract}

Keywords: Warehouse Operation, Supply Chain Management, Hub and Spoke.

\section{Introduction}

The supply chain management is the process in which the raw material is processed into finished goods which reaches the customers. In the due course the flow of product with respect to storage is to be mentioned as warehouse. The storage of goods in warehouse can either be raw material or partially finished goods or even finished goods. Each and every process in the flow is measured with respect to the value addition done to the product. The value addition with respect to customising of product can be efficient done at warehouse, hence the warehouse operation not only act as storage place but also helps in adding value to the product. These applications eventually classified warehouses into different categories such as Production warehouse, Distribution warehouse, etc. These classifications were made according to the production and distributions requirement of the products as per the customer requirement.

\section{Warehouse Operation}

The warehouse operations comprises of receiving the good which can be either raw material or finished goods, further storage and replenishment process takes place which proceed to distribution. The storage process can be sub categorised with various operations such as sorting, packaging, customising, etc. The warehousing operations require various associated operations to enhance the efficiency such as safety standard operations, delivery centre operations, etc. Hence the efficiency is aggregated with numerous factors put forth in the supply chain management.

The contribution of Logistics operations cannot be avoided at any circumstance in the due course of Warehouse management. Each and every transaction of goods is associated with logistics operation along with efficient material handling. There are various technology incorporated to add value in the process, such as Automation in material handling, Computer programming in managing the data of the product and customer.

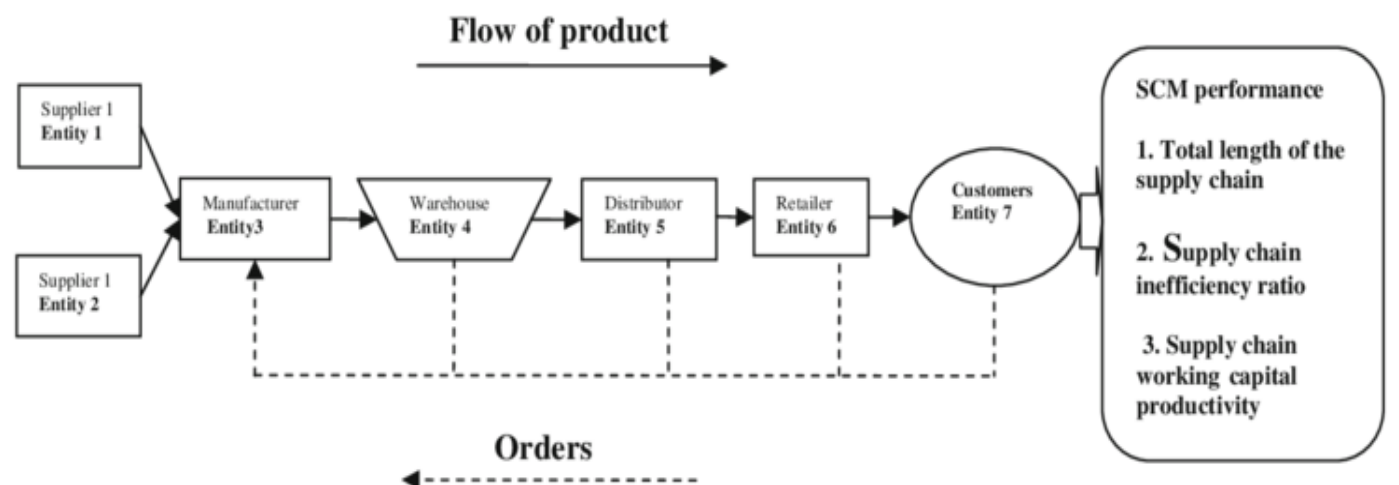

Source: https://www.researchgate.net/figure/Company-supply-chain-network_fig4_263735704 


\section{Significance of Warehouse Management}

The important need of warehouse management is well seen in receiving orders and processing it in order to attain the desired output. The significance of warehouse management lies in meeting the demand of day to day operations. This management technique avoids the waste such as reduction in redoing of work, misplacement of materials, accessing optimum inventory and so on. This organising way of technique helps the operations to be carried out within the controlled scale limits, this eventually assist in maintaining quality parameters.

This are helps in sorting and organising the data which ultimately helps in tracking and identifying any particular product individually. The major key challenge lies in reducing the warehouse maintenance cost. Increase in quality at times is directly proportional to increase in cost.

\section{Technological Integration}

The warehouse management integrate technology in various domains. The automation in the process can be enhanced by the utilization of Robotics technology. The robots are utilized in material handling along with the integration of Radio Frequency Identification (RFID). This could eventually reduce the errors. With respect to computer programming the data management of material handling can be done efficiently by incorporating the Material Resource Planning and Enterprise Resource Planning tools.

This planning software's helps in efficient management of inventory with on time replenishment and maintaining optimum quantity on a real time basis. The utilization of QR code or barcode along with wireless technology will eventually add additional advantage to the process. It is also important to maintain flexible approach in order to accommodate the futuristic changes emerge in the due process. The complex process in the operations may extend into the overlapping of the process, increase in re processing work, etc. These re processing work require addition time and energy which had the chance to avoid totally if proper attention given to it.

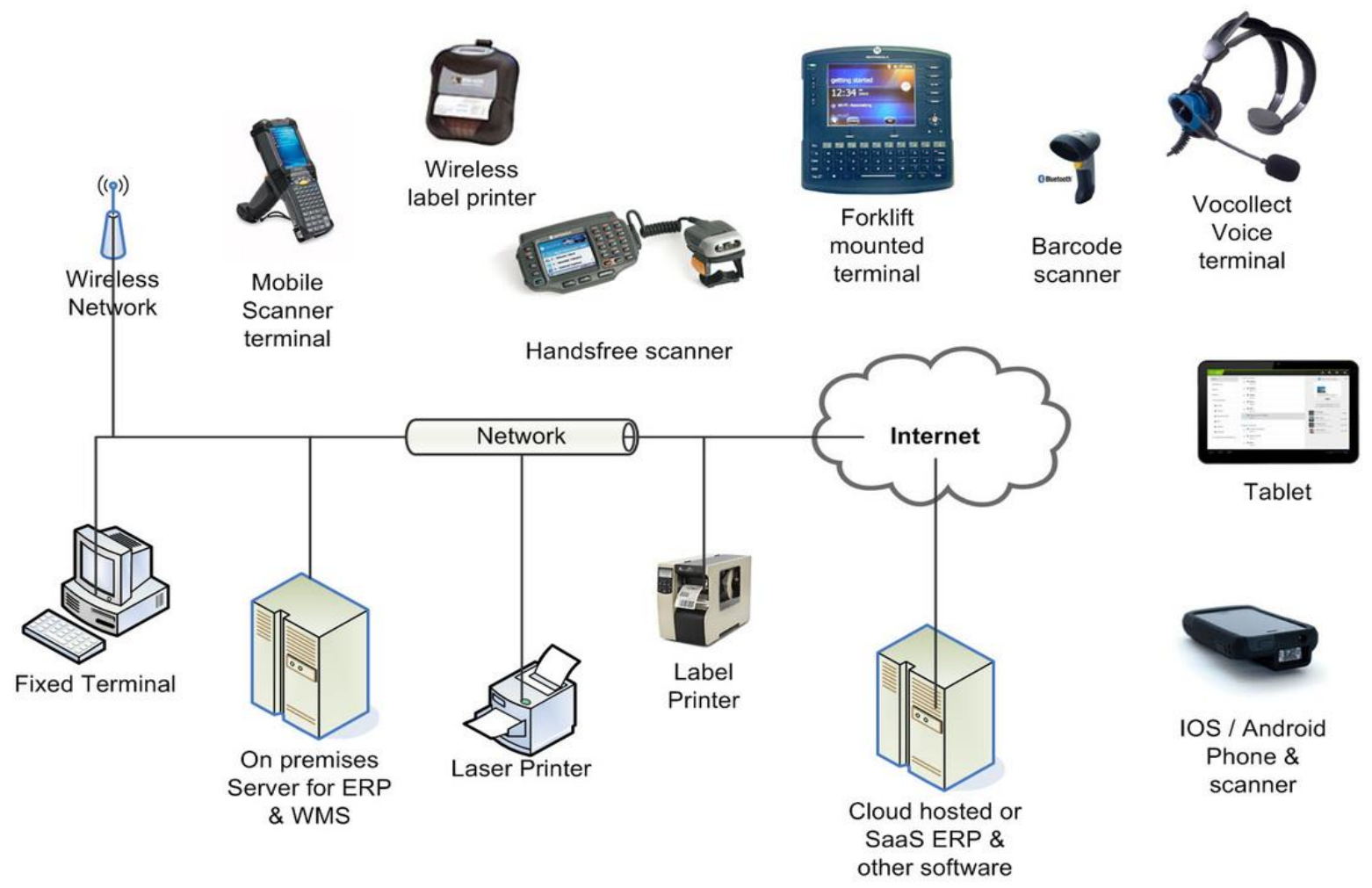

Source: https://logisticshelp.com/warehouse-management-systems/

\section{Analysis of Data}

The primary data is collected with the help of questionnaire where the sample size lies more than four hundred participants. The Participant or subjects were the employees working in logistics and ware house management firms located in Chennai city. 
The analyses are as follows:

- As per the analysis of data the inclination is towards positive orientation such as moderate which is $35.4 \%$ and High which is $30.7 \%$ is stated. The clearly defines that the employees are looking for effective warehouse management techniques, this could help in meeting the key demands of the customer.

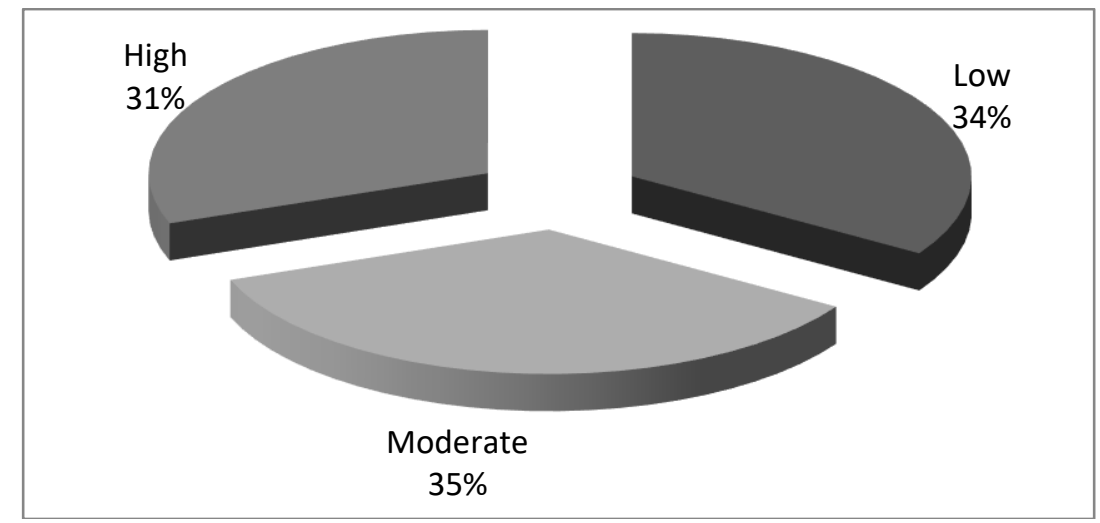

Table 1. Total Warehouse Descriptive Statistics (Percentages)

\begin{tabular}{lrl}
\hline & \multicolumn{2}{c}{ Frequency } \\
\hline Low & 145 & 34.0 \\
Moderate 151 & 35.4 \\
High & 131 & 30.7 \\
\hline Total & $\mathbf{4 2 7}$ & $\mathbf{1 0 0 . 0}$ \\
\hline
\end{tabular}

- The interpretation of Mean and Standard deviation states that the responses were above the average which is considered to be 3 . The data recorded were above the mean value which 3 . Hence most of the respondents are looking for effective standard operating procedures with respect to warehouse management. The Standard deviation with respect to data also states the values are more than one hence deviates from low possibility towards higher possibility of integrating efficient warehouse management.

Table 2. Total Warehouse Descriptive Statistics (Mean \& SD)

\begin{tabular}{lll}
\hline Hub and spoke model ensures centralization of operations & Mean & Std. Deviation \\
Hub and Spoke model leads to effective inventory management & 3.26 & 1.185 \\
In Hub and Spoke model SOPs are easily followed & 3.37 & 1.113 \\
Hub and Spoke model ensures implementation of safety parameters & 3.33 & 1.169 \\
Hub and Spoke model reduces warehousing related problems & 3.18 & 1.169 \\
Hub and Spoke model involves use of analytical tools & 3.30 & 1.170 \\
Hub and Spoke model helps in effective network analysis & 3.30 & 1.215 \\
Hub and Spoke model ensures accumulation of authentic data & 3.38 & 1.095 \\
Hub and Spoke model enables use of extensions with fixed hub locations 3.34 & 1.218 \\
Hub and Spoke model enables efficient recycling/reusing of waste & 3.26 & 1.237 \\
\hline
\end{tabular}

\section{Advantages of Effective Warehouse Management}

Some of the key advantage are as follows
a) Increase in reduction of errors.
b) Increase in optimum accuracy.
c) Effective implementation of cost control measures.
d) Effective utilisation of resources such land, capital and labour.
e) Reduction in lead time.
f) Increase in data and information accuracy.
g) Optimum inventory management.
h) Easy identification and tracking, etc... 
The integration of warehouse management in an organisation requires huge capital outflow and time taking process. It can be done at one stretch; the process has to fit with every value added stations in a unique way to meet the demand.

The people handling the operations in warehouse has to have a clear vision about every value added approaches in the supply chain management including the customers' feedback.

\section{Conclusion}

In the challenging competitive environment, it has become very much essential and un avoidable to incorporate the effective Warehouse management process. Only an effective warehouse management could result in sustainable competitive advantage. A well executed warehouse management will obviously applauded and encourage by the customers which will not only result in profit but also enhances the knowledge base in the field of supply chain management. This effective warehouse management will eventually reduce the bottle neck in the supply chain process hence enhances the data management, cost optimisation and forecasting of demand.

\section{References}

1. Harris, C.M. (2006). Dictionary of architecture and construction. McGraw-Hill.

2. Cormier, G., \& Gunn, E.A. (1992). A review of warehouse models. European journal of operational research, 58(1), 3-13.

3. Wheeler, M. (1972). Renfrew: "The emergence of civilisation: the Cyclades and the Aegean in the third millennium BC" (Book Review). Antiquity, 46(184), 327-329.

4. Rickman, G. (1971). Roman granaries and store buildings. CUP Archive.

5. Mitch, D. (1990). Public Warehousing, 42.2. Handbook of American Business History: Extractives, manufacturing, and services, 2, 377.

6. Schulz, J. (2004). The new palaces of Medieval Venice. Penn State Press.

7. Carus-Wilson, E.M. (2013). Medieval Merchant Venturers: Collected Studies. Routledge. 